\title{
1 Development of a copper-graphene nanocomposite based transparent 2 coating with antiviral activity against influenza virus
}

4 Indrani Das Jana ${ }^{1 \#}$, Partha Kumbhakar ${ }^{2 \#}$, Saptarshi Banerjee ${ }^{1}$, Chinmayee Chowde Gowda ${ }^{3}$, Nandita 5 Kedia $^{1}$, Saikat Kumar Kuila ${ }^{2}$, Sushanta Banerjee ${ }^{4}$, Narayan Chandra Das ${ }^{5}$, Amit Kumar Das ${ }^{1}$, Indranil 6 Manna $^{2}$, Chandra Sekhar Tiwary ${ }^{2 *}$, Arindam Mondal ${ }^{*}$

${ }^{1}$ School of Bioscience, Indian Institute of Technology Kharagpur, India

$9 \quad{ }^{2}$ Department of Metallurgical and Materials Engineering, Indian Institute of Technology Kharagpur, India

$10{ }^{3}$ School of Nanoscience and Technology, Indian Institute of Technology Kharagpur, India

$11{ }^{4}$ Material Science Center, Indian Institute of Technology Kharagpur, India

$12{ }^{5}$ Rubber Technology Center, Indian Institute of Technology Kharagpur, India

13 \# Authors contributed equally

* Address for correspondence: arindam.mondal@iitkgp.ac.in, chandra.tiwary@metal.iitkgp.ac.in

Keywords: Nanocomposite, Influenza virus, Nano-Luciferase, Antivirals coating

\section{Abstract}

Respiratory infections by RNA viruses are one of the major burdens upon global health and economy. Viruses like influenza or coronaviruses can be transmitted through respiratory droplets or contaminated surfaces. An effective antiviral coating can decrease the viability of the virus particles in the outside environment significantly, hence reducing their transmission rate. In this work, we have screened a series of nanoparticles and their composites for antiviral activity using Nano Luciferase based highly sensitive influenza A reporter virus. Using this screening system, we have identified copper-graphene (Cu-Gr) nanocomposite shows strong antiviral activity. Extensive material and biological characterization of the nanocomposite suggested a unique metal oxide embedded graphene sheet architecture that can inactivate the virion particles only within 30 minutes of pre-incubation and subsequently interferes with the entry of these virion particles into the host cell. This ultimately results in reduced viral gene expression, replication and production of progeny virus particles, slowing down the overall pace of progression of infection. Using PVA as a capping agent, we have been able to generate a $\mathrm{Cu}-\mathrm{Gr}$ nanocomposite based highly transparent coating that retains its original antiviral activity in the solid form. 


\section{Introduction}

37 The emergence of novel virus strains and the associated outbreaks are becoming a significant threat to 38 mankind (Koven 2020). The currently ongoing pandemic, caused by the Severe Acute Respiratory 39 Syndrome- Coronavirus 2 (SARS-CoV-2), has brought the majority of the world to a grinding halt, severely 40 impacting health \& economy across the nations (Letko, Marzi, and Munster 2020). So far, the COVID-19 41 pandemic has claimed 720,000 lives resulting from 19.4 million infections globally. This reminds us of the great 1918 Spanish flu pandemic by the influenza virus, which resulted in 500 million infections with 50 million deaths (Johnson and Mueller 2002) (Patterson and Pyle 2019) (Taubenberger and Morens 2006) (Landrigan et al. 2018). Till date, there have been four worldwide pandemics caused by influenza viruses in the last century $(1918,1957,1968,2009)$ (World Health Organization 2018) (Saunders-Hastings and Krewski 2016), while Covid19 is the first pandemic caused by the Coronavirus (Y. Wu et al. 2020). Other than pandemics, influenza A and B viruses cause seasonal outbreaks (290,000 to 650,000 deaths worldwide: CDC FLUVIEW] and different coronaviruses cause mild flu-like symptoms to severe respiratory infections (SARS (De Wit et al. 2016) and MERS (Lin et al. 2019) coronavirus epidemics during 2002 and 2012 respectively) (Fehr and Perlman 2015). Clearly, recurring respiratory infections caused by these viruses are becoming one of the global human health problem.

Both influenza and coronaviruses cause respiratory infections, which can be transmitted from infected to healthy individuals through respiratory droplets, aerosols or contacts. These respiratory pathogens are known for their ability to persist on inanimate surfaces for days and even up to months, depending upon weather conditions (Vasickova et al. 2010). As a result, touching contaminated surfaces in public places is a potential route of viral transmission. In fact, the inanimate surfaces have been identified as a major cause of infections, especially in institutions where individuals are in contact with patients or contaminated fomites. Thus, the development of low cost and easily scalable antiviral coating materials, which could be widely applied to various surfaces in order to inactivate the virus particles in the environment, may serve as an effective way to reduce the chance of infection and hence to lower the overall speed of transmission.

Different metal oxides, including $\mathrm{Cu}$ and $\mathrm{Ag}$ have been explored for their biocidal activity in soluble as well as in insoluble forms (Minoshima et al. 2016). Copper and silver nanoparticles have remarkable properties like high electrical and thermal conductivity (Barani et al. 2020; D. Deng et al. 2013), superior catalytic nature (Gawande et al. 2016), anti-fungal (Cioffi et al. 2005) and bacteriostatic activities (Ruparelia et al. 2008) to name a few. Solid-state cuprous oxide and silver nitrate have been shown to inactivate virus 
the attachment of the virus to the host cell receptors (Fehr and Perlman 2015) (Sunada, Minoshima, and Hashimoto 2012). Cuprous oxide nanoparticles had also been shown to inhibit the attachment and entry stages of Hepatitis C Virus infection, hence suggesting a generic mechanism for the copper-based nanoparticles for their antiviral activities (Hang et al. 2015). This may also explain the lesser viability of infectious SARS-CoV-2 particles on copper surfaces $(8 \mathrm{~h})$ when compared to stainless steel and plastic surfaces (72 h) (Neeltje van Doremalen et al. 2020). Biological activity of the $\mathrm{Cu}$ or $\mathrm{Ag}$ nanoparticles largely depends upon their size, shape, stability and capping agent. Due to the high reactivity of these nanoparticles, they can undergo rapid agglomeration leading to the drastic reduction of their activity (Ma et al. 2011). One way to overcome this instability is to form a composite with other organic or inorganic compounds which stabilizes the nanoparticles by altering their surface architecture (Perdikaki et al. 2018).

Graphene is composed of a single atom thick sheet of $\mathrm{sp} 2$ hybridized carbon atoms that forms a honeycomb lattice (Mohammed et al. 2020; Palmieri and Papi 2020). This structure of graphene is responsible for its large surface area, excellent electrical conductivity, strong mechanical strength and unique physicochemical properties (Edwards and Coleman 2013; Eigler and Hirsch 2014; Novoselov et al. 2012). It is used extensively in the field of nano-medicine due to easy surface functionality and controlled selectivity (Park et al. 2020). In recent times, the two dimensional sheet of graphene has caught much attention due to its antimicrobial and antiviral activity (Georgakilas et al. 2012). Differentially functionalized graphene oxide sheets can warp and encapsulate microorganisms, thereby severely restricting their interaction with host cells (Perdikaki et al. 2018) (Vinothini and Rajan 2017) (Karahan et al. 2018). For example, sulfate functionalized reduced graphene oxide has been shown to interact with the positively charged surface proteins of different orthopoxvirus strains (Ziem et al. 2016) (Ye et al. 2015). In this work, we have performed an extensive investigation of the potential antiviral activity of copper $(\mathrm{Cu})$ nanoparticles, silver (Ag) nanoparticles, graphene (Gr) and their hybrid versions (nanocomposite materials) Ag-graphene, $\mathrm{Cu}$ graphene and $\mathrm{Ag}-\mathrm{Cu}$-graphene against respiratory viruses using influenza A virus as a model system. Our data shows that prior incubation with the colloidal $\mathrm{Cu}-\mathrm{Gr}$ nanocomposite can impose a strong reduction in viral infectivity, which gets manifested in the reduced viral entry, gene expression and subsequent production of progeny virions. Extensive material characterization using UV-Visible absorption and Raman spectroscopy along with X-Ray Diffraction (XRD) reveals a unique architecture of copper oxide decorated two-dimensional graphene sheets. The shape, size and distribution of the hybrid nanoparticles were also studied using Scanning Electron Microscopy (SEM) and Energy-dispersive X-ray spectroscopy (EDAX).

100 Finally, we have developed for the first time a polyvinyl alcohol (PVA) based copper-graphene 101 nanocomposite coating, which is completely transparent and shows strong antiviral activity in the solid 102 phase. 


\section{Results}

\section{Synthesis and preliminary characterization of the nanoparticles and nanocomposites}

106

107

108

109

We have synthesized various nanoparticles and their hybrids using a simple and cost-effective chemical method as discussed in the experimental section. The synthesized materials are $\mathrm{Cu}$ nanoparticles, $\mathrm{Ag}$ nanoparticles, graphene (Gr) and their hybrid versions Ag- graphene, $\mathrm{Cu}$ - graphene and Ag-Cu-graphene (Figure 1 A, B). Visible absorption spectra of each of these variants confirms the presence of respective components either alone or in combination with their composite partners, as shown in Figure $1 \mathrm{C}$ and $\mathrm{D}$. The peak at $418 \mathrm{~nm}$ confirms the formation of Ag colloidal nanoparticles (Jin et al. 2005). From literature, it is attributed to Surface Plasmon Resonance with spherical nature (Hu et al. 2013). From the UV-vis spectra of the composite Ag-Gr, Plasmon absorption band at around $410 \mathrm{~nm}$, indicates the formation of a hybrid structure. Incorporation of Ag nanoparticles on graphene sheets had led to a blue shift of the surface plasmon resonance, a characteristic similar to previous reports (Kim et al. 2018).

Furthermore, $\mathrm{Cu}$ nanoparticles, due to exposure of air at room temperature, goes through surface oxidation, which is the reason that samples contain oxygen in +1 and +2 states forming $\mathrm{CuO}$ or $\mathrm{Cu}_{2} \mathrm{O}$ ( $\mathrm{Yao}$ et al. 2005). Composite including both $\mathrm{Ag}$ and $\mathrm{Cu}$ nanoparticles were also analyzed from the absorption spectrum. A broad graphene peak was observed at $280 \mathrm{~nm}$ in the composite. Both $\mathrm{Ag}$ and Cu nanoparticle plasmon peaks were observed and confirmed the presence of the colloidal nanoparticles on graphene sheets (Darabdhara et al. 2017). Particularly, Figure 1D shows the absorption spectra of the composites and it confirms the formation of graphene and $\mathrm{CuO} / \mathrm{Cu}_{2} \mathrm{O}$ nanoparticles. An absorption peak at $262 \mathrm{~nm}$ is due to $\pi \rightarrow \pi^{*}$ transition in $\mathrm{C}=\mathrm{C}$ bond of graphene. Another absorption band at $350-450 \mathrm{~nm}$ is attributed to the intrinsic band to band transition of the $\mathrm{CuO}$ and $\mathrm{Cu}_{2} \mathrm{O}$ (Zhang et al. 2020). A blue shift was observed in the peak position compared to bulk $\mathrm{CuO}$; this might be due to the quantum confinement effects exhibited by the particle when the size varies from bulk to nano. These UV-Vis peaks were well matched with $\mathrm{CuO}$ and $\mathrm{Cu}_{2} \mathrm{O}$ absorption profiles from previous studies (Chan et al. 2007). A broadened plasmon resonance peak for $\mathrm{Cu}-\mathrm{Gr}$ nanocomposites is due to irregular shapes and sizes of the particles (Zhang et al. 2020).

\section{Screening of nanoparticles and their hybrids for antiviral activity}

To test the antiviral activity of synthesized nanomaterials and their composites we have used a bioluminescent reporter variant of the influenza A virus, strain A/H1N1/WSN/1933, that has been previously reported by Tran et al. (Tran et al. 2013). This virus has a Nano-Luciferase (NLuc) gene fused to the carboxy-terminal of the viral PA gene, interspaced by the "self-cleaving" 2A peptide encoding 
134 sequence from porcine teschovirus. The Nano-Luc-influenza A reporter virus, as a part of its gene 135 expression, synthesizes the PA-2A-NLuc polypeptide, which gets self-cleaved to produce Nano-luciferase. 136 Subsequently, the luciferase activity could be measured as a quantitative estimate of viral gene expression 137 and hence progression of virus replication cycle inside the cells. To test whether the Nano-luciferase activity 138 could actually serve as a proxy to virus replication, we have infected MDCK cells with different amounts 139 of input virus and viral replication/gene expression was monitored using Nano-Glo assay (Promega). As 140 shown in Figure 3A, there is a linear relationship between multiplicity of infection (0.01-0.1) and luciferase 141 light unit measurements $\left(\mathrm{R}^{2}=0.9294\right)$, where an increase in one log in the input virus amount leads to about $14250 \%$ increase in the luciferase activity or vice versa, measured at 8 hours of post-infection. This data 143 suggests that the Nano-luciferase influenza A reporter virus could serve as an excellent tool to study the antiviral activity of various nanoparticles or their nanocomposites used in this study.

145 In order to test the antiviral activity, we have standardized a "Nano-Luc reporter assay" described in Figure 146 3B. Briefly, Nano-luciferase influenza A reporter viruses were pre-incubated with the 5uM colloidal 147 suspensions of each of the nanoparticles/ composites or with the vehicle control for 30 minutes at room 148 temperature and subsequently used to infect MDCK cells at an MOI of 0.1. Luciferase activity was 149 measured at 8 hours of post infection and plotted as a relative percentage of the vehicle control set (Figure

$1503 \mathrm{C}$ ). Prior treatment of the virus stock solution with $\mathrm{Cu}-\mathrm{Gr}$ composite showed $64 \%$ reduction in viral gene 151 expression, while prior treatment with Ag-Gr resulted in 20\% reduction. Treatment with other materials 152 shows no significant decrease in luciferase activity. From the correlation of input virus units and the 153 corresponding luciferase activity, as shown in Figure 3A, it can be inferred that prior treatment with $\mathrm{Cu}-\mathrm{Gr}$ 154 solution resulted in more than 10-fold reductions in the infectious virus population that has been used to 155 infect the MDCK cells. In this context, it should be noted that none of the materials showed substantial 156 cytotoxicity upon Madin-Darby Canine Kidney cells (MDCK) within the concentration range of $0.5 \mathrm{uM} \mathrm{-}$ $1575.0 \mathrm{uM}$ as evaluated using MTT assay (Figure 2). Hence, the reduction in Nano-luciferase activity as a 158 result of prior exposure to $\mathrm{Cu}-\mathrm{Gr}$ should be attributed exclusively to the reduction of the infectivity of the 159 Nano-luciferase reporter virus. Henceforth, we focused upon the extensive characterization of the $\mathrm{Cu}-\mathrm{Gr}$ 160 nanocomposite.

\section{Material characterization of $\mathrm{Cu}-\mathrm{Gr}$ nanocomposite}

163 We have extensively characterized the structural parameters of the synthesized $\mathrm{Cu}-\mathrm{Gr}$ nanocomposites by 164 optical measurements. Figure 4 A depicts Raman spectra of synthesized $\mathrm{Cu}-\mathrm{Gr}$ nanocomposite samples at 165 excitation of $532 \mathrm{~nm}$ in the range of $200 \mathrm{~cm}^{-1}$ to $3000 \mathrm{~cm}^{-1}$. With Raman spectroscopy, we are able to 166 distinguish both pristine graphene and copper peaks. The presence of D peak $\left(1361 \mathrm{~cm}^{-1}\right)$ and $\mathrm{G}$ peak $(1527$ 
$167 \mathrm{~cm}^{-1}$ ) confirms the existence of graphene in the samples synthesized. Generally, D peak originates from 168 defects in the hexagonal $\mathrm{sp}^{2}$ carbon system while the $\mathrm{G}$ peak arises due to the stretching vibration of $\mathrm{sp}^{2}$ 169 carbon pairs in both rings and chains (Ferrari et al. 2006). Except, D and G peak, the 2D peak arises at $170 \sim 2700 \mathrm{~cm}^{-1}$. The 2D peak originates due to transverse optical (TO) phonons around the $\mathrm{K}$ point and is

171 activated by triple resonance Raman scattering (TRRS) (J. Bin Wu et al. 2018). In the measured Raman 172 spectra (Figure 4B), three peaks are $\left(280 \mathrm{~cm}^{-1}, 350 \mathrm{~cm}^{-1}\right.$ and $\left.654 \mathrm{~cm}^{-1}\right)$ observed to confirm the formation 173 of oxide of $\mathrm{Cu}$ and originate due to the first order phonon scattering. The peaks are assigned to $\mathrm{A}_{\mathrm{g}}$ and $2 \mathrm{~B}_{\mathrm{g}}$ 174 peaks of copper oxide (Y. Deng et al. 2016). The graphene sheets are also seen in the optical images, as 175 shown in the inset of Figure $4 \mathrm{~A}$. Figure 4B shows the XRD patterns of graphene, $\mathrm{CuO}$, and $\mathrm{Cu}_{2} \mathrm{O}$ 176 nanoparticles, which confirm the crystalline phase of composites samples (standard JCPDS file number 35177 0505, 80-1917). Interestingly, the intensity of the $\mathrm{Cu}_{2} \mathrm{O}$ is more intense compared to that of the $\mathrm{CuO}$ peaks, 178 suggesting a higher abundance of $\mathrm{Cu}_{2} \mathrm{O}$ on the surface of the graphene sheets. No diffraction peaks 179 corresponding to impurities are observed in the patterns.

\section{Extensive characterization of antiviral property of Colloidal Cu-Gr nanocomposite}

182 Followed by the material characterization, we have invested significant efforts for the characterization of 183 the antiviral property of the $\mathrm{Cu}-\mathrm{Gr}$ nanocomposites in its colloidal form. First, we have used the Nano-Luc 184 reporter assay in order to identify the optimal time and concentration required for its antiviral activity. The 185 Nano-Luc reporter assay was performed where the influenza A reporter virus was pretreated with the 186 colloidal form of the $\mathrm{Cu}-\mathrm{Gr}$ nanocomposite for various time periods before using them for infecting MDCK 187 cells. As evidenced from Figure 5A, a sharp decrease (>50\%) in the reporter activity was observed as a 188 result of 30 minutes of preincubation with $\mathrm{Cu}-\mathrm{Gr}$ composite, while longer times of preincubation showed 189 only minor additional reduction. This data suggested that 30 minutes of preincubation with $\mathrm{Cu}-\mathrm{Gr}$ 190 composite can lead to more than tenfold reduction in input virus titer that ultimately results in $\sim 50 \%$ 191 decrease in reporter activity. Subsequently, we tried to identify the optimal concentration of the Cu-Gr 192 composite required for its antiviral activity. Different concentrations of the Cu-Gr composite (50nM, $193100 \mathrm{nM}, 500 \mathrm{nM}, 1 \mu \mathrm{M}, 2 \mu \mathrm{M}$ and $5 \mu \mathrm{M}$, respectively) were used to treat the Nano-Luc influenza A reporter 194 virus for 30 minutes followed by performing Nano-Luc reporter assay with the same. A precise dose 195 dependent decrease in reporter activity and hence virus replication was observed as a result of prior 196 treatment with $\mathrm{Cu}-\mathrm{Gr}$ composite within the concentration range of $0.5 \mathrm{mM}$ to $5 \mathrm{mM}$ (Figure $5 \mathrm{~B}$ ). While 197 higher concentration $(10 \mu \mathrm{M})$ further reduced reporter activity, it may also show cytotoxicity upon the cells, 198 hence excluded from the subsequent experiment. 
Next, we intended to test whether the reduction in the luciferase activity of the reporter virus, as a result of pretreatment with $\mathrm{Cu}-\mathrm{Gr}$ nanocomposite, can also be correlated to the reduction of progeny virus titer. A non-reporter variant of the influenza A/H1N1/WNS/1933 virus was used for this purpose. Virus stock solutions were either treated with two different concentrations of $\mathrm{Cu}-\mathrm{Gr}$ nanocomposites $(1 \mu \mathrm{M}$ and $5 \mu \mathrm{M})$ or with the vehicle control prior to infection on MDCK cells. Plaque assay was performed to measure the titer of the progeny virus particles harvested at 8 hours of post-infection. There is about $40 \%$ decrease in viral titer for the sets treated $5 \mathrm{uM} \mathrm{Cu}-\mathrm{Gr}$ solution with respect to the vehicle treated sets. Treatment with $1 \mu \mathrm{M} \mathrm{Cu}-\mathrm{Gr}$ nanocomposite shows non-significant decrease in viral titer. This data further substantiates the fact that treatment with $5 \mu \mathrm{M} \mathrm{Cu}-\mathrm{Gr}$ significantly reduces viral infectivity which results in a decrease in viral gene expression, replication and subsequent production of viral titer (Figure 5C). The plaque assay titer data are tabulated in Figure 5D.

\section{Prior treatment with $\mathrm{Cu}-\mathrm{Gr}$ nanocomposite explicitly inhibits virus entry into the cells}

213 At this point, we sought to examine the molecular mechanism by which $\mathrm{Cu}-\mathrm{Gr}$ nanocomposite interferes

214 with virus replication cycle. Metal nanoparticles have been shown to interfere with the integrity of the virus

215 particles or the activity of the surface glycoproteins that may interfere with the entry of virus particles into

216 the host cells (Sunada, Minoshima, and Hashimoto 2012) (Ting Du. 2018). Hence, to investigate the effect

217 of pretreatment of $\mathrm{Cu}-\mathrm{Gr}$ specifically upon virus entry step, we have performed an 'entry assay' (Figure

218 6A). The non-reporter variant of Influenza A WSN virus were either treated with $\mathrm{Cu}$-Gr or with solvent

219 and subsequently used to infect MDCK cells in a synchronized fashion. Post entry, cells were incubated

220 with cycloheximide containing media for one hour to allow the import of the incoming viral 221 ribonucleoprotein complexes (RNPs) into the nucleus. Subsequently, the incoming viral RNPs were stained 222 with antibodies specific to viral Nucleoprotein (NP), which is the major component of the RNPs. As shown 223 in the Figure 6 B, input viral RNPs are solely detected inside the nucleus of the infected cells irrespective 224 of the treatment. However, prior exposure to the $\mathrm{Cu}-\mathrm{Gr}$ composite resulted in a significant reduction in the 225 number of NP positive cells. A quantitative analysis of 5 different fields with a total of 500 cells for both 226 treated and untreated sets shows roughly $80 \%$ decrease in number of NP positive cells in the $\mathrm{Cu}-\mathrm{Gr}$ treated 227 set, with respect to the untreated one (Figure 6C). This data clearly suggests that exposure to $\mathrm{Cu}-\mathrm{Gr}$ 228 nanocomposite compromises the ability of the virus particles to enter into the host cell, possibly by 229 impacting the structural integrity of the of the virion particles.

\section{Development of a $\mathrm{Cu}-\mathrm{Gr}$ nanocomposite based transparent coating with strong antiviral activity}

232 The ability of $\mathrm{Cu}-\mathrm{Gr}$ nanocomposite to reduce the infectivity of influenza A virus prompted us to test its ability to inactivate influenza virus in the solid form. For this purpose, we have coated different wells of a 
23448 well plate with a series of coating solutions containing different concentrations of $\mathrm{Cu}-\mathrm{Gr}$ composite

$235(1 \mu \mathrm{M}, 5 \mu \mathrm{M}, 10 \mu \mathrm{M}$ and $20 \mu \mathrm{M})$ and polyvinyl alcohol (PVA) (1mm, 5mm, and 10mm) as a capping agent.

236 As a control, wells were coated with only PVA. This process generated a thin transparent film of Cu-Gr

237 nanocomposite onto the surface of each well. To test the antiviral activity of these films, defined amounts

238 of Nano-Luc influenza A reporter virus were inoculated in these coated wells and incubated for 30 minutes.

239 Post treatment, infectivity of these virus inoculums were tested on MDCK cells using the Nano-Luc reporter

240 assay as mentioned above. Prior exposure to the coating materials having various concentrations of $\mathrm{Cu}-\mathrm{Gr}$

241 composite blended in different amounts of PVA resulted in differential effects upon viral replication (Figure

242 7). Films containing different concentrations of $\mathrm{Cu}-\mathrm{Gr}$ composite, either in absence or in presence $1 \mathrm{mM}$

243 PVA barely showed any impact upon the infectivity of the virus. In contrast, an exact dose-dependent

244 decrease in viral gene expression was observed as a result of prior treatment with the films containing

245 increasing concentrations of Cu-Gr Composite in 5mM PVA. This antiviral activity was even more

246 pronounced (70\% decrease in Nano-Luc activity) for the films containing 1-5uM of Cu-Gr with $10 \mathrm{mM}$ of

247 PVA. Together, this data shows $5 \mathrm{uM}$ of $\mathrm{Cu}-\mathrm{Gr}$ composite capped with $10 \mathrm{mM}$ of PVA could be used to

248 generate a transparent coating with high antiviral activity.

249 Encouraged by the results mentioned above, we have used dip-coating method used to coat a tempered

250 glass with the $\mathrm{Cu}$-Gr solution with optimum concentration. The glass unit was kept to soak the solution for

$25124 \mathrm{~h}$ and then air-dried naturally as shown in (Figure 8A). No formation of visibly aggregated spots or

252 clogging was observed on the glass surface. A clean, transparent screen was obtained, and when fixed on a

253 cell phone, there was no compromisation of light intensity or clarity of image on the display screen observed

254 (Figure 8B). Optical transmittance spectra confirm the transparency of the coating on glass substrates

255 (Figure 8C). As observed from the SEM images (Figure 8D), the $\mathrm{Cu}-\mathrm{O}$ nanoparticles were uniformly

256 embedded on top of the graphene layer. Elemental analysis of $\mathrm{Cu}-\mathrm{Gr}$ compounds was conducted by color

257 mapping and EDAX analysis. The data presented in the right panel of Figure 8D and Figure 8E confirmed

258 the presence of $\mathrm{C}, \mathrm{O}$, and $\mathrm{Cu}$ elements in the composites sample and their uniform distribution in the sample.

259 Figure $8 \mathrm{~F}$ shows a schematic representation of the $\mathrm{Cu}_{2} \mathrm{O}$ and $\mathrm{CuO}$ nanoparticles embedded on the graphene

260 sheets with PVA as a binding agent.

262 Discussions

263 RNA viruses constitute one of the broader families of human pathogens, including influenza, Nipah, Ebola,

264 SARS or MERS-Coronaviruses. Irrespective of their specific differences in virus replication cycle, all of

265 these viruses share broader structural similarities. The viral genomic RNA remains enwrapped with single

266 or multiple viral proteins and remains enclosed within the lipid bilayer envelope embedded with viral spike 
proteins. The integrity of the lipid envelope and the functionality of the spike proteins are not only crucial for the protection of the viral genomic materials in the outer environment but also indispensable for conducting the first two steps of the virus life cycle that are "attachment" and "entry" (Jane Flint, Vincent $\mathrm{R}$ 2015). In this study, we have identified $\mathrm{Cu}-\mathrm{Gr}$ nanocomposite as a potential antiviral agent that can interfere with these two steps of the influenza A virus life cycle, possibly through compromising the

272 structural integrity of the virion particles.

273 We, for the first time, have used a highly sensitive Nano-Luc reporter assay to perform an unbiased 274 screening of a series of nanoparticles and their composite materials in order to identify a coating substance 275 with strong antiviral activity. Our data identified $\mathrm{Cu}-\mathrm{Gr}$ nanocomposite as the most potential antiviral agent.

276 Interestingly, $\mathrm{Cu}$ nanoparticles or graphene individually showed minimal or no antiviral activity in our 277 assay while a hybrid between these two showed at least ten-fold decrease in effective viral titer. This might 278 be due to the property of the composite substances, which is not just a hybrid between two materials in their original state, but rather a combination of the modified version of the materials (Ramakrishnan et al. 2015).

280 This can also be substantiated from the previous studies showing metal-ion based composites shows better activity compared to that of metal nanoparticles itself(Minoshima et al. 2016; Perdikaki et al. 2018; Sunada, Minoshima, and Hashimoto 2012). Studies also reveal that the antiviral activity mainly depends on the presence of ions generated from the surface of nanoparticles (Ma et al. 2011) (Shen et al. 2010). Our XRD data clearly indicates the presence of various copper oxide species, $\mathrm{Cu}_{2} \mathrm{O}$ and $\mathrm{CuO}$, embedded in the graphene sheets which may serve as the basis for the antiviral activity of the composite material. The presence of reactive oxygen species in $\mathrm{Cu}_{\mathrm{x}} \mathrm{O}$-graphene sheets may provide ions, which may interfere with the structural integrity of the lipid bilayer membrane or the surface antigens of the virion particles. This interference should compromise the ability of the virus particles to interact with the cell surface receptor essential for the attachment and subsequent entry into the host cell. Our entry assay supports this hypothesis, as prior treatment with $\mathrm{Cu}-\mathrm{Gr}$ composite resulted in significant reduction in the percentage of infection positive cells with respect to the vehicle treated set.

292 Finally, we have used PVA as a capping agent and identified optimum concentrations of $\mathrm{Cu}-\mathrm{Gr}$ and PVA 293 to develop a thin transparent coating with intense antiviral activity. While we have used dip-coating method 294 to coat a tempered glass with high visibility, other forms of coatings like doctor's blade technique, spin 295 coating, and spray coating can also be implemented. Due to the high transmission efficiency, such coating 296 material could be implemented on a wide variety of surfaces, which could radically decrease the stability 297 of the virus particles in the outer environment and hence reduce the transmission rate drastically. Needless 298 to mention that such generic antiviral strategy can significantly reduce the overall burden of seasonal 
respiratory infection-related epidemics or occasional pandemics caused either by various influenza or coronaviruses.

\section{Materials and Methods}

302 Chemicals:

303 Copper sulfate $\left(\mathrm{CuSO}_{4}>99 \%\right)$, Silver nitrate $\left(\mathrm{AgNO}_{3}>99 \%\right)$, Sodium borohydride $\left(\mathrm{NaBH}_{4}>98 \%\right)$, Poly

304 vinyl alcohol ( $>99 \%)$, Sodium hydroxide pellets $(\mathrm{NaOH}>97 \%)$ and graphite powder $(>98 \%)$ were

305 purchased from Sigma-Aldrich.

Cells, Viruses and Antibody: Madin Darby Canine Kidney (MDCK) (CCL-34) cells were maintained in Dulbecco's modified Eagle's medium (DMEM) supplemented with 5\% FBS at $37^{\circ} \mathrm{C}$ and $5 \% \mathrm{CO}_{2}$ along with penicillin and streptomycin antibiotics (Gibco).

Influenza A virus strains, A/WSN/1933 (H1N1), WSN stably encoding PB2 with a C-terminal FLAG tag on the strain A/WSN/33 (H1N1) were used for infecting the cells (Tran et al. 2013). Antibody used includes anti-NP (H16-L10-4R5) (Yewdell et al., 1981).

\section{Synthesis of materials:}

317 Initially, the graphene dispersion was prepared using a liquid exfoliation of the graphite powder in 318 Deionized (DI) water $(20 \mathrm{mg} / 300 \mathrm{~mL})$ using an ultrasonic probe sonicator. Probe sonication of frequency $31930 \mathrm{~Hz}$ was used in pulses for 2 hours. Silver $(\mathrm{Ag})$ and Copper $(\mathrm{Cu})$ stock solutions were prepared using $3204 \mathrm{mM} \mathrm{AgNO}_{3}(68 \mathrm{mg} / 100 \mathrm{~mL})$ and $4 \mathrm{mM} \mathrm{CuSO}_{4}(63.8 \mathrm{mg} / 100 \mathrm{~mL})$ in DI water medium respectively. 321 Graphene solution ( $45 \mathrm{~mL}$ ) was mixed with $15 \mathrm{~mL}$ of Cu and $\mathrm{Ag}$ stock solution separately by maintaining 322 the $\mathrm{pH}=12$ adjusted through $\mathrm{NaOH} .20 \mathrm{~mL}$ of $4 \mathrm{mM} \mathrm{NaBH}_{4}(30 \mathrm{mg} / 200 \mathrm{~mL})$ solution, a strong reducing 323 agent is added drop wise with the $\mathrm{Cu}$-graphene ( $\mathrm{Cu}-\mathrm{Gr}), \mathrm{Ag}$-graphene (Ag-Gr) and $\mathrm{Cu}$ - $\mathrm{Ag}$-graphene $(\mathrm{Cu}-$ 324 Ag-Gr) mixtures separately and stirred continuously at $40^{\circ} \mathrm{C}$.

325 Furthermore, four different concentrations $(1 \mu \mathrm{M}, 5 \mu \mathrm{M}, 10 \mu \mathrm{M}$ and $20 \mu \mathrm{M})$ of $\mathrm{Cu}$ functionalized graphene 326 samples were synthesized for biological process optimization. Three different concentrations $(1 \mathrm{mM}, 5 \mathrm{mM}$ 327 and $10 \mathrm{mM}$ ) of poly vinyl alcohol have been capped as a coating media for the $\mathrm{Cu}$-graphene samples.

\section{Material characterizations:}

330 Different phases of the synthesized sample $(\mathrm{Cu}$ functionalized graphene) were obtained from the $\mathrm{X}$-ray 331 diffraction (XRD) peaks by using Bruker D8 Advance X-ray diffractometer within a scan range of 2Theta 
332 (20) values 7 and $90^{\circ}$ with $\mathrm{Cu}-\mathrm{K} \alpha$ source, maintaining the scan rate of $1^{\circ} \mathrm{min}^{-1}$. Absorption spectra of $\mathrm{Cu}-$

333 graphene synthesized sample were recorded by a BioTek UV-vis spectrophotometer Epoch 2 microplate 334 within $200 \mathrm{~nm}$ to $800 \mathrm{~nm}$ wavelength. Raman shifts were measured by using WiTec -alpha 300R confocal

335 microscope at excitation of $532 \mathrm{~nm}$ in the wavenumber range of $200 \mathrm{~cm}^{-1}$ to $3000 \mathrm{~cm}^{-1}$. SEM images were

336 obtained through Zeiss-Merlin EVO 60 scanning electron microscope with Oxford EDS detector.

338 MTT assay:

339 MDCK cells were seeded in 96 well plates at a density of 15000 cells per well. The cells were treated with 340 Silver (Ag), Graphene (Gr), Copper $(\mathrm{Cu})$ nanoparticles as well as Ag-Gr, $\mathrm{Cu}-\mathrm{Gr}$ and $\mathrm{Ag}-\mathrm{Cu}-\mathrm{Gr}$ 341 nanocomposites respectively for 24 hours $(\mathrm{h})$ at $37^{\circ} \mathrm{C}$ in $5 \% \mathrm{CO}_{2}$. Cellular cytotoxicity assay was performed 342 according to the manufacturer's protocol. In brief, after $24 \mathrm{~h}$ of treatment with the nanoparticle, $100 \mu 1$ of 343 MTT reagent ( $5 \mathrm{mg} / \mathrm{ml}, \mathrm{SRL})$ in PBS was added to the cells and incubated for $3 \mathrm{~h}$ at $37^{\circ} \mathrm{C}$. The medium 344 was removed carefully without disturbing the formazan crystals and $100 \mu$ l of DMSO (Sigma) was added 345 to dissolve the insoluble purple formazan crystals. The absorbance of the suspension was measured at 595 $346 \mathrm{~nm}$ using Epoch 2 Microplate Reader (BioTek instruments). The percentages of metabolically active cells 347 were compared with the percentage of control cells of the same culture plate as a proxy for cell viability. 348 Cellular cytotoxicity was determined in triplicate and each experiment was repeated three times 349 independently.

Nano-Luc reporter assay:

352 The Nano-Luc reporter assay was used to determine the luciferase activity as previously mentioned by Tran 353 et al., 2013 (Tran et al. 2013). MDCK cells seeded in a 96 well plate were infected in triplicate with the 354 Nano Luciferase influenza A reporter virus, PASTN. Accordingly, the virus was preincubated with a 355 particular concentration of the nanoparticle/nanocomposite for $30 \mathrm{~min}$ or mentioned otherwise. The vehicle 356 control or the nanoparticle/ nanocomposite treated virus was used to infect MDCK cells. The infected cells 357 were harvested at $8 \mathrm{hpi}$ and the viral NLuc activity was measured by using Nano-Glo® Luciferase Assay 358 System according to the manufacturer's instructions (Promega) and the luminescence was detected by using 359 a Luminometer (Glomax 20/20, Promega).

\section{Plaque assay:}

362 A non-reporter variant of the influenza A/H1N1/WSN/1933 virus stock solutions MOI 0.1 was either 363 preincubated with vehicle control or $\mathrm{Cu}-\mathrm{Gr}$ nanocomposite (1 $\mathrm{uM}$ and $5 \mathrm{uM})$ followed by infection in MDCK 364 cells. At 8hpi, the viral supernatant was collected and used to reinfect MDCK cells and plaque assay was 
performed to determine the progeny viral titer followed by Matrosovich M, 2006 (Matrosovich et al. 2006). Accordingly, after $1 \mathrm{hr}$ of infection with the virus, cells were overlaid with a media containing a mixture of 2X DMEM and 2.4\% avicel (1:1 ratio). After $62 \mathrm{hrs}$, the overlay was discarded and the cells were fixed with $70 \%$ ethanol followed by staining with $2 \%$ Crystal violet. Plaques were counted and plaque forming unit (PFU/ml) was calculated to measure the progeny viral titer.

\section{Viral entry assay:}

MDCK cells grown on coverslips were infected with vehicle control or $5 \mathrm{uM} \mathrm{Cu}-\mathrm{Gr}$ treated virus at a MOI of 5. Viral entry assay was performed according to the protocol followed by Mondal et al., 2017 (Mondal et al. 2017). Virion binding was performed at $4^{\circ} \mathrm{C}$ for $1 \mathrm{hr}$ in presence of $1 \mathrm{mM}$ of Cycloheximide, CHX (Sigma). The viral inoculum was washed off with cold PBS to remove unbound virus particles. Thereafter, the prewarmed virus growth media (VGM, containing DMEM, $0.2 \%$ bovine serum albumin (BSA), $25 \mathrm{mM}$ HEPES buffer, and $0.5 \mathrm{mg} / \mathrm{ml}$ TPCK-trypsin) supplemented with $1 \mathrm{mM}$ of CHX was added to the cells and synchronous infection was initiated by shifting cells to $37^{\circ} \mathrm{C}$. At $1 \mathrm{hpi}$, cells were fixed with $3 \%$ formaldehyde and permeabilized with $0.1 \mathrm{M}$ Glycine/0.1\% Triton-X 100 in PBS for 20 min at room temperature. Blocking was performed at $4{ }^{\circ} \mathrm{C}$ with $3 \% \mathrm{BSA}$ overnight. NP was detected with anti-NP antibody and Alexa Fluor 555-conjugated donkey anti-mouse IgG antibody (Invitrogen). DAPI (Sigma) was used to stain the nucleus. Cells were imaged using Fluorescent microscope (Leica Microsystems) and image analysis was performed with ImageJ software.

\section{Statistics:}

Each data is a representative of at least three independent experiments, each experiment was performed in triplicate. Graphs are performed in Microsoft Excel and represented as mean standard deviations $(\mathrm{n}=3)$. Results were compared by performing two-tailed Student's $t$ test. Significance is defined as $p<0.05$ and statistical significance is indicated with an asterisk $(*)$. The *p value $<0.05, * * \mathrm{p}$ value $<0.01 * * \mathrm{p}$ value and $* * * \mathrm{p}<0.001$ were considered statistically significant.

\section{Acknowledgement:}

We sincerely thank Prof. Andrew Mehle, University of Wisconsin Madison, for providing the Nano-Luc influenza A reporter viruses. This work was primarily supported by Sponsored Research and Industrial Consultancy (SRIC) IIT Kharagpur. AM would like to thank DBT for Ramalingaswami re-entry fellowship, SERB for Early Career Research Award and MHRD for the "Scheme for Transformational and Advanced Research in Science" for additional financial support. 


\section{References}

Barani, Zahra et al. 2020. "Thermal Properties of the Binary-Filler Hybrid Composites with Graphene and Copper Nanoparticles.” Advanced Functional Materials 30(8): 1-11.

Chan, George H. et al. 2007. "Plasmonic Properties of Copper Nanoparticles Fabricated by Nanosphere Lithography." Nano Letters 7(7): 1947-52.

Cioffi, Nicola et al. 2005. "Copper Nanoparticle/Polymer Composites with Antifungal and Bacteriostatic Properties." Chemistry of Materials 17(21): 5255-62.

Darabdhara, Gitashree et al. 2017. "Cu-Ag Bimetallic Nanoparticles on Reduced Graphene Oxide Nanosheets as Peroxidase Mimic for Glucose and Ascorbic Acid Detection." Sensors and Actuators, B: Chemical 238: 842-51.

Deng, Dunying et al. 2013. "Copper Nanoparticles: Aqueous Phase Synthesis and Conductive Films Species.” ACS Catalysis 6(4): 2473-81.

Edwards, Rebecca S., and Karl S. Coleman. 2013. "Graphene Synthesis: Relationship to Applications." Nanoscale 5(1): 38-51.

Eigler, Siegfried, and Andreas Hirsch. 2014. "Chemistry with Graphene and Graphene Oxide Challenges for Synthetic Chemists.” Angewandte Chemie - International Edition 53(30): 7720-38.

Fehr, Anthony R, and Stanley Perlman. 2015. "Coronaviruses: An Overview of Their Replication and Pathogenesis." Methods in molecular biology (Clifton, N.J.) 1282: 1-23. 97(18): 1-4.

Gawande, Manoj B. et al. 2016. "Cu and Cu-Based Nanoparticles: Synthesis and Applications in Catalysis." Chemical Reviews 116(6): 3722-3811.

Georgakilas, Vasilios et al. 2012. "Functionalization of Graphene: Covalent and Non-Covalent Approach." Chemical Reviews 112(11): 6156-6214.

Hang, Xiaofeng et al. 2015. "Antiviral Activity of Cuprous Oxide Nanoparticles against Hepatitis C Virus in Vitro." Journal of Virological Methods 222: 150-57.

$432 \mathrm{Hu}$, Yanjie et al. 2013. "Scalable Preparation of Ultrathin Silica-Coated Ag Nanoparticles for SERS 
Application." ACS Applied Materials and Interfaces 5(21): 10643-49.

Jane Flint, Vincent R, Glen F Rall and Anna Marie with Lynn W Enquist. 2015. Principles of Virology, 4th Edition.

Jin, Rongchao, Justin E. Jureller, Hee Y. Kim, and Norbert F. Scherer. 2005. "Correlating Second Harmonic Optical Responses of Single Ag Nanoparticles with Morphology." Journal of the American Chemical Society 127(36): 12482-83.

Johnson, Niall P.A.S., and Juergen Mueller. 2002. "Updating the Accounts: Global Mortality of the 19181920 'Spanish’ Influenza Pandemic.” Bulletin of the history of medicine 76(1): 105-15.

Karahan, Hüseyin Enis et al. 2018. "Graphene Materials in Antimicrobial Nanomedicine: Current Status and Future Perspectives." Advanced Healthcare Materials 7(13): 1-18.

Kim, Un Jeong et al. 2018. "Anomalous K-Point Phonons in Noble Metal/Graphene Heterostructure Activated by Localized Surface Plasmon Resonance.” ACS Nano 12(12): 12733-40.

Koven, S. 2020. “Engla, Journal - 2010 - New Engla Nd Journal.” New England Journal of Medicine: 12.

Landrigan, Philip J. et al. 2018. "The Lancet Commission on Pollution and Health.” The Lancet 391(10119): 462-512.

Letko, Michael, Andrea Marzi, and Vincent Munster. 2020. "Functional Assessment of Cell Entry and 5(4): 562-69.

Lin, Leon Chien Wei et al. 2019. "Viromimetic STING Agonist-Loaded Hollow Polymeric Nanoparticles for Safe and Effective Vaccination against Middle East Respiratory Syndrome Coronavirus." Advanced Functional Materials 29(28): 1-15.

Ma, Jizhen et al. 2011. "Preparation, Characterization and Antibacterial Properties of Silver-Modified Graphene Oxide." Journal of Materials Chemistry 21(10): 3350-52.

Matrosovich, Mikhail, Tatyana Matrosovich, Wolfgang Garten, and Hans Dieter Klenk. 2006. "New

$$
\text { Low-Viscosity Overlay Medium for Viral Plaque Assays." Virology Journal 3: 1-7. }
$$

Minoshima, Masafumi et al. 2016. "Comparison of the Antiviral Effect of Solid-State Copper and Silver Compounds." Journal of Hazardous Materials 312: 1-7.

Mohammed, Hiba et al. 2020. "Antimicrobial Mechanisms and Effectiveness of Graphene and GrapheneFunctionalized Biomaterials. A Scope Review.” Frontiers in Bioengineering and Biotechnology 8(May).

Mondal, Arindam et al. 2017. "Influenza Virus Recruits Host Protein Kinase C to Control Assembly and Activity of Its Replication Machinery." eLife 6: 1-23.

Neeltje van Doremalen, PhD et al. 2020. "Aerosol and Surface Stability of SARS-CoV-2 as Compared 
with SARS-CoV-1.” New England Journal of Medicine: 0-2.

Novoselov, K. S. et al. 2012. “A Roadmap for Graphene.” Nature 490(7419): 192-200. http://dx.doi.org/10.1038/nature11458.

Palmieri, V., and M. Papi. 2020. "Can Graphene Take Part in the Fight against COVID-19?" Nano Today 33: 100883 .

Park, Se Jin et al. 2020. "Discovery of Direct-Acting Antiviral Agents with a Graphene-Based Fluorescent Nanosensor.” Science Advances 6(22): 1-12.

Patterson, David, and Gerald Pyle. 2019. "The Geography and Mortality of the 1918 Influenza Pandemic." Bulletin of the History of Medicine 65(1): 4-21.

Perdikaki, Anna et al. 2018. "Ion-Based Metal/Graphene Antibacterial Agents Comprising Mono-Ionic and Bi-Ionic Silver and Copper Species." Langmuir 34(37): 11156-66.

Ramakrishnan, S. et al. 2015. "One-Step Synthesis of Pt-Decorated Graphene-Carbon Nanotubes for the Electrochemical Sensing of Dopamine, Uric Acid and Ascorbic Acid." Analytical Methods 7(2): 779-86.

Ruparelia, Jayesh P., Arup Kumar Chatterjee, Siddhartha P. Duttagupta, and Suparna Mukherji. 2008. "Strain Specificity in Antimicrobial Activity of Silver and Copper Nanoparticles." Acta Biomaterialia 4(3): 707-16.

Dos Santos Afonso, Emmanuel et al. 2005. "The Generation of Recombinant Influenza A Viruses Expressing a PB2 Fusion Protein Requires the Conservation of a Packaging Signal Overlapping the Coding and Noncoding Regions at the 5' End of the PB2 Segment.” Virology 341(1): 34-46.

Saunders-Hastings, Patrick R., and Daniel Krewski. 2016. "Reviewing the History of Pandemic Influenza: Understanding Patterns of Emergence and Transmission.” Pathogens 5(4).

Shen, Jianfeng et al. 2010. "Facile Synthesis and Application of Ag-Chemically Converted Graphene Nanocomposite." Nano Research 3(5): 339-49.

Sunada, Kayano, Masafumi Minoshima, and Kazuhito Hashimoto. 2012. "Highly Efficient Antiviral and Antibacterial Activities of Solid-State Cuprous Compounds.” Journal of Hazardous Materials 235236: 265-70. http://dx.doi.org/10.1016/j.jhazmat.2012.07.052.

Taubenberger, Jeffery K., and David M. Morens. 2006. "1918 Influenza: The Mother of All Pandemics." Emerging Infectious Diseases 12(1): 15-22.

Ting Du., et al. 2018. "Antiviral Activity of Graphene Oxide-Silver Nanocomposites_2018.Pdf."

Tran, V., L. A. Moser, D. S. Poole, and A. Mehle. 2013. "Highly Sensitive Real-Time In Vivo Imaging of an Influenza Reporter Virus Reveals Dynamics of Replication and Spread.” Journal of Virology 87(24): 13321-29.

Vasickova, P, I Pavlik, M Verani, and A Carducci. 2010. "Issues Concerning Survival of Viruses on 
Surfaces." Food and Environmental Virology 2(1): 24-34.

Vinothini, Kandasamy, and Mariappan Rajan. 2017. "Investigation on the Use of Graphene as a Unique Drug Delivery Platform for Dissimilar Anticancer Drugs.” Progress in Bioscience and Bioengineering 1(1): 11-17.

De Wit, Emmie, Neeltje Van Doremalen, Darryl Falzarano, and Vincent J. Munster. 2016. "SARS and MERS: Recent Insights into Emerging Coronaviruses.” Nature Reviews Microbiology 14(8): 52334.

World Health Organization. 2018. "The Top 10 Causes of Death.” World Health Organization.

$\mathrm{Wu}$, Jiang Bin et al. 2018. "Raman Spectroscopy of Graphene-Based Materials and Its Applications in Related Devices." Chemical Society Reviews 47(5): 1822-73.

Wu, Yuntao et al. 2020. "SARS-CoV-2 Is an Appropriate Name for the New Coronavirus." The Lancet 395(10228): 949-50.

Yao, Wei Tang et al. 2005. "Formation of Uniform CuO Nanorods by Spontaneous Aggregation: Process." Journal of Physical Chemistry B 109(29): 14011-16.

Ye, Shiyi et al. 2015. "Antiviral Activity of Graphene Oxide: How Sharp Edged Structure and Charge Matter." ACS Applied Materials and Interfaces 7(38): 21578-79.

Zhang, Zhuanfang et al. 2020. "Facile Hydrothermal Synthesis of CuO-Cu2O/GO Nanocomposites for

Ziem, Benjamin et al. 2016. "Highly Efficient Multivalent 2D Nanosystems for Inhibition of

$$
\text { Orthopoxvirus Particles." Advanced Healthcare Materials 5(22): 2922-30. }
$$

\section{Figure legends}

Figure 1. Different nanoparticles and their nanocomposites. (A) Digital photographs of all the nanoparticles embedded two dimensional graphene sheets. (C-D) UV-Vis absorption spectra of synthesized nanoparticles and their composites. 

assay (Promega). To demonstrate the relationship between the MOI and luciferase activity (arbitrary unit) was plotted as a function of MOI. (B) To test the antiviral activity, the Influenza A reporter virus was pretreated with the $5 \mathrm{uM}$ colloidal suspensions of each of the materials for 30 minutes at RT and followed

542 by infection of MDCK cells at MOI of 0.1as diagrammed. (C) Luciferase activity of the nanoparticle/

543 nanocomposite treated sets were measured at $8 \mathrm{hpi}$ and plotted as a relative percentage of the vehicle treated set. For all experiments, data are mean of $\mathrm{n}=3 \pm$ standard deviation $(*, \mathrm{P}<0.05 ; \mathrm{n}=3 \pm \mathrm{sd})$.

Figure 4. Material characterization of the $\mathrm{Cu}-\mathrm{Gr}$ nanocomposite. (A) Raman spectrum of $\mathrm{Cu}-\mathrm{Gr}$ nanocomposites. Inset shows optical microscopy image of the composite and Raman spectrum of $\mathrm{Cu}_{\mathrm{x}} \mathrm{O}$. (B) XRD spectrum of composites sample confirming the presence of $\mathrm{CuO}, \mathrm{Cu}_{2} \mathrm{O}$, and $\mathrm{Graphene}$ virus. (A) A time kinetics experiment was performed by treating Influenza A reporter virus with $5 \mathrm{uM}$ colloidal suspensions of $\mathrm{Cu}-\mathrm{Gr}$ for 15, 30, 45 and $60 \mathrm{~min}$ at RT and followed by infection of MDCK cells at MOI 0.1. Absolute luciferase activity values w.r.t viral gene expression for the vehicle and $\mathrm{Cu}-\mathrm{Gr}$ treated sets are represented by black and grey bars respectively. (B) MDCK cells were infected with Influenza A reporter virus pretreated with vehicle or with different concentrations of the $\mathrm{Cu}-\mathrm{Gr}$ composite (50nM, $100 \mathrm{nM}, 500 \mathrm{nM}, 1 \mathrm{uM}, 2 \mathrm{uM}$ and $5 \mathrm{uM}$ respectively). Viral gene expression was monitored using luciferase activity assay. Data were normalized to vehicle control sets for each nanoparticle. (C, D) A non-reporter vehicle control prior to infecting MDCK cells. Plaque assay was performed to measure the titer of the progeny virus particles harvested at 8hpi. Percentage reduction in viral titers and actual PFUs for all experiments are represented. For all experiments, data are mean of $n=3 \pm$ standard deviation $(*, P<0.05$; $\mathrm{n}=3 \pm \mathrm{sd})$. of Entry assay: MDCK cells were infected with influenza A virus either pretreated with $5 \mathrm{uM} \mathrm{Cu}-\mathrm{Gr}$ or with vehicle control. Synchronous infection was carried out by incubating the virus inoculum with the cell monolayer at $4^{0} \mathrm{C}$ for one hour, followed by adding the virus growth media (VGM) supplemented with cycloheximide and prewarmed at $37^{\circ} \mathrm{C}$. Cells were incubated further for one hour before processing them

568 for imaging (B) Intracellular localization of viral NPs in control and Cu-Gr treated sets were determined by 569 staining with anti NP antibody and Alexa Fluor 555 (red). DAPI was used to stain the nucleus (Blue). (C) 
Percentage of NP positive cells in control and in treated sets were analyzed using image $\mathrm{J}$ software and depicted by bar diagram. For all experiments, data are mean of $n=5 \pm$ standard deviation $(*, P<0.05)$. a 48 well plate was coated with coating solutions having different concentrations of $\mathrm{Cu}-\mathrm{Gr}$ composite (1uM,

$5745 \mathrm{uM}, 10 \mathrm{uM}$ and $20 \mathrm{uM})$ and polyvinyl alcohol (PVA) (1mM, 5mM and 10mM). Nano LuciferaseInfluenza A virus (MOI 0.1) were inoculated in these wells and incubated for 30 minutes. Post treatment, MDCK cells were infected with the viral inoculum recovered from the coated wells and luciferase activity was determined at 8 hpi using Nano-Glo reporter assay (Promega). Luciferase activity of each set was plotted as a relative percentage of the vehicle treated set. Each data was represented in triplicate and each experiment was repeated three times. Data are presented as means \pm standard deviations $(\mathrm{SD})(\mathrm{n}=3)(*, \mathrm{P}<$ $0.05)$. coating of the cell phone screen. (A) Schematic diagram of the deep coating method of tempered glass unit with the PVA based Cu-Gr nanocomposite. (B) Transparency of dip coated tempered mobile screen. (C) Transmittance spectrum of the coated sample. (D) SEM image of $\mathrm{Cu}$-Graphene composites sample. presence of $\mathrm{Cu}, \mathrm{C}$ and $\mathrm{O}$ atoms. (F) Schematic representation of the composite structure. 


\section{Figure 1}

A

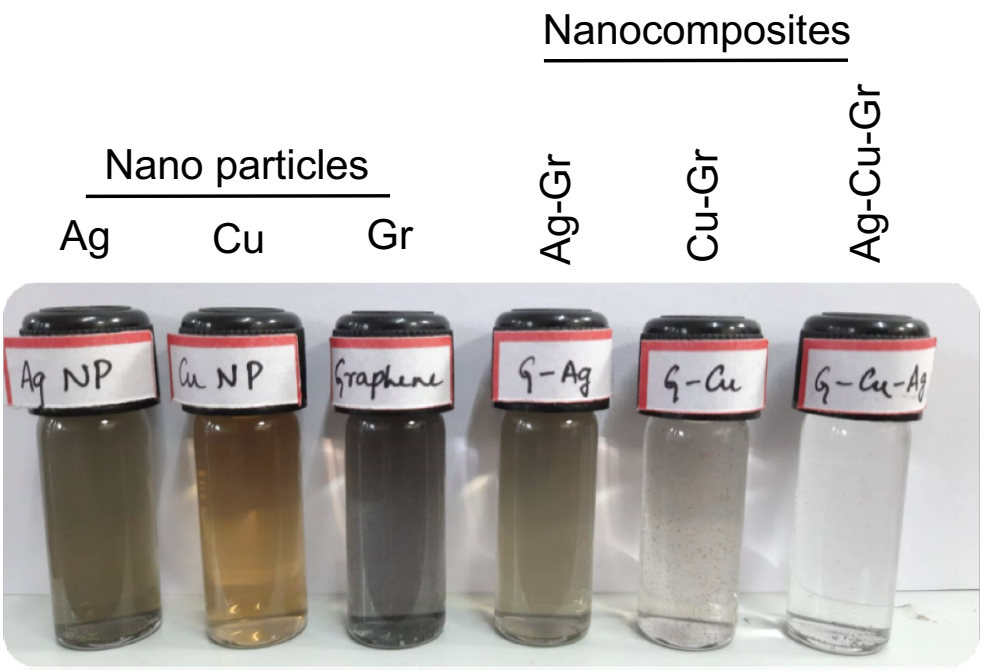

C

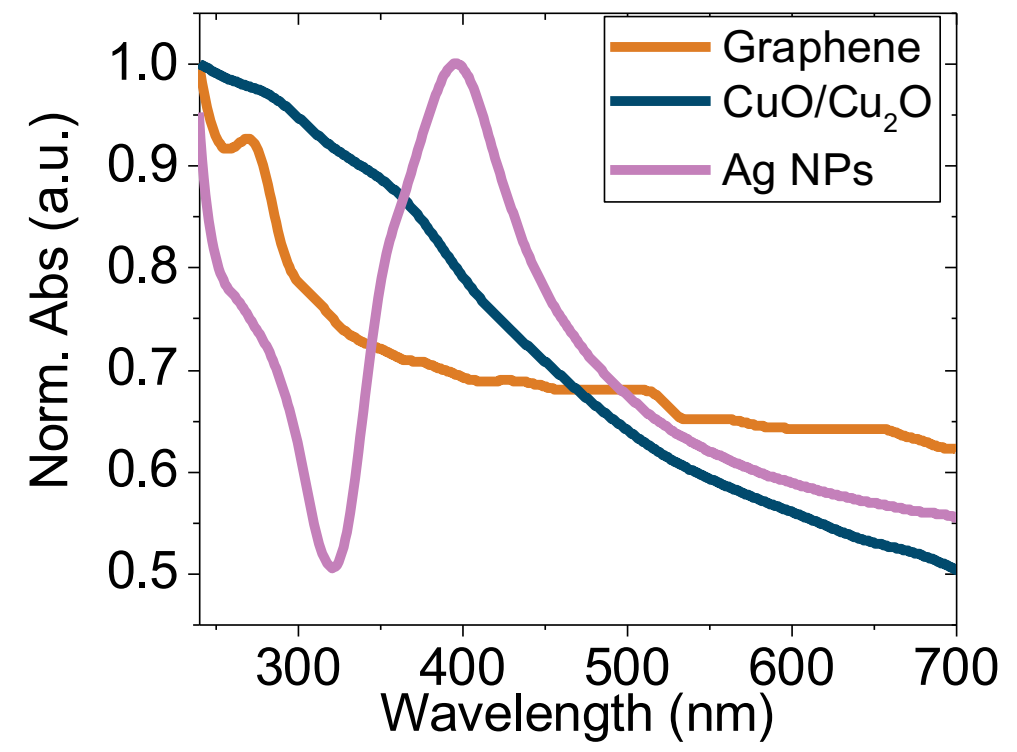

B
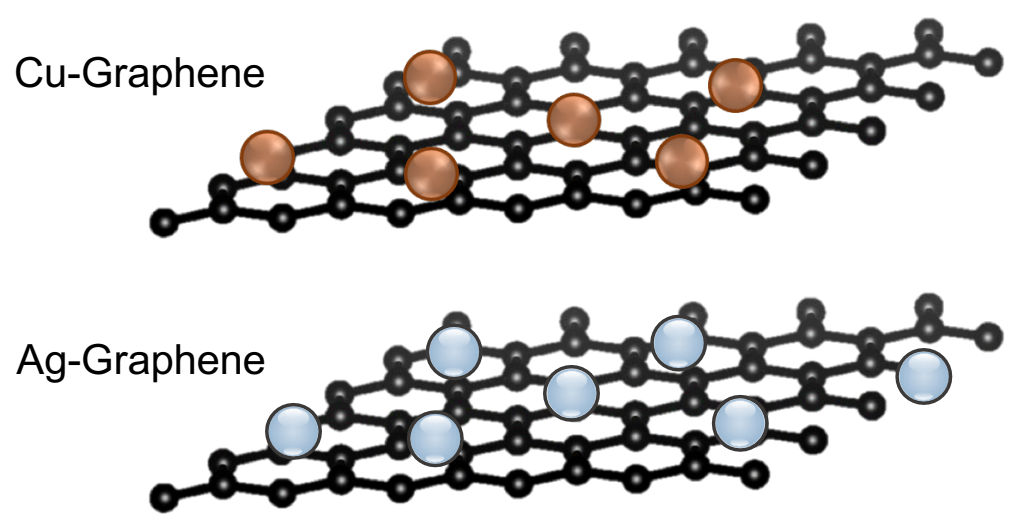

CuO/ $/ \mathrm{Cu}_{2} \mathrm{O}$ Nanoparticles

Ag Nanoparticles

D

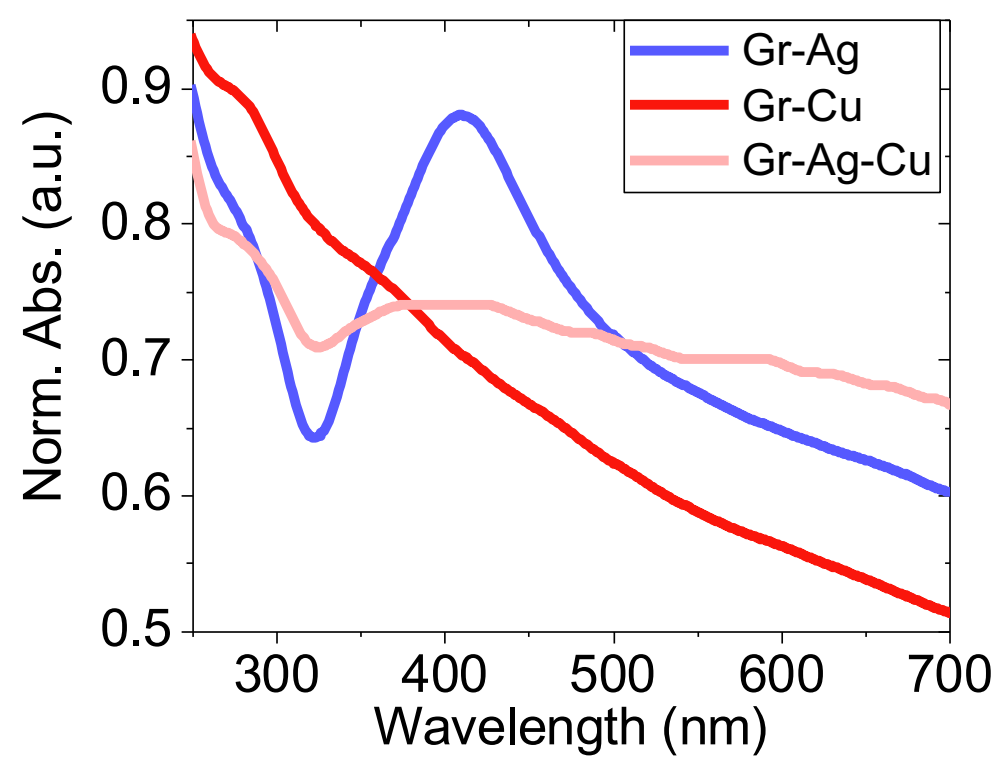


Figure 3

A B
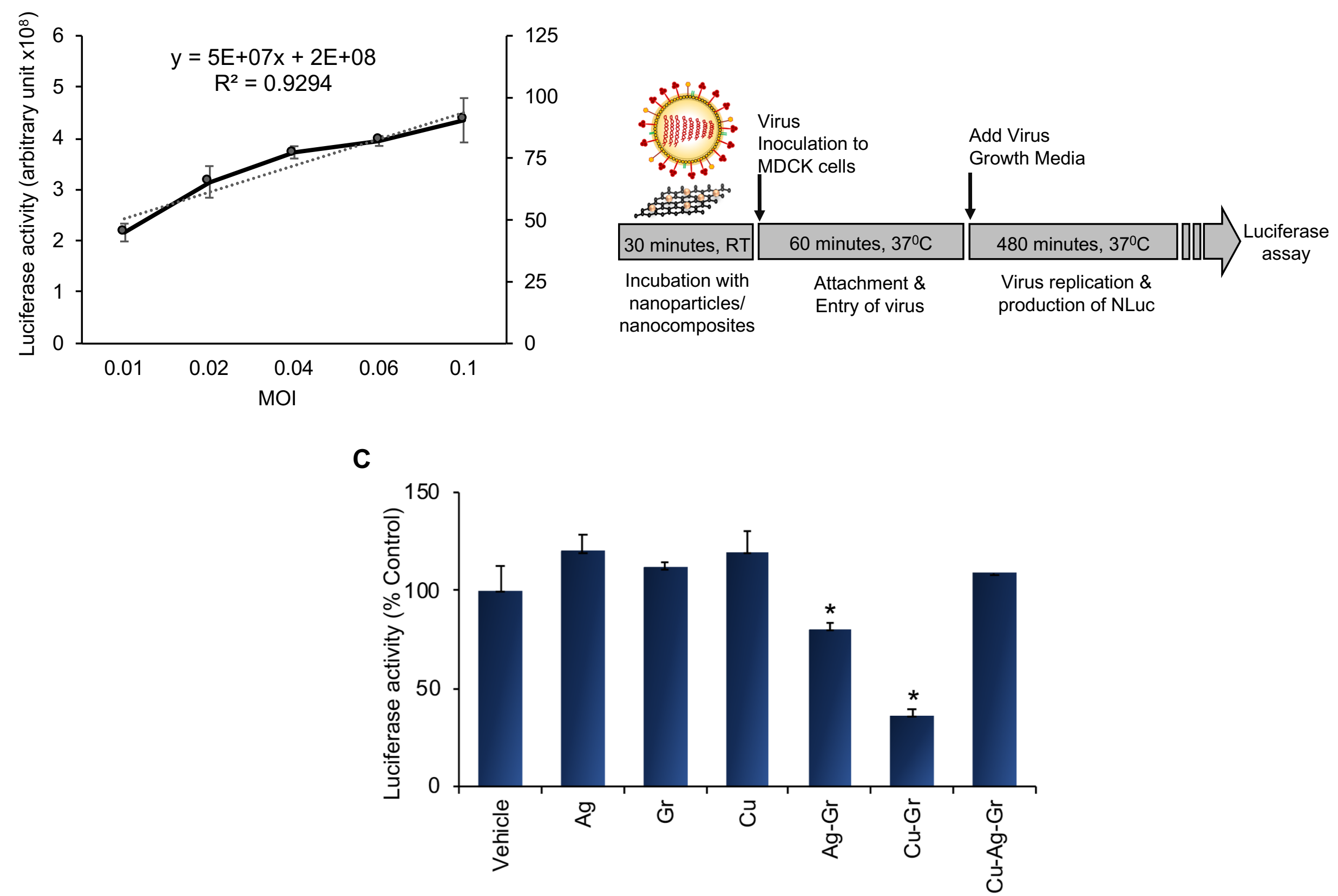
Figure 4
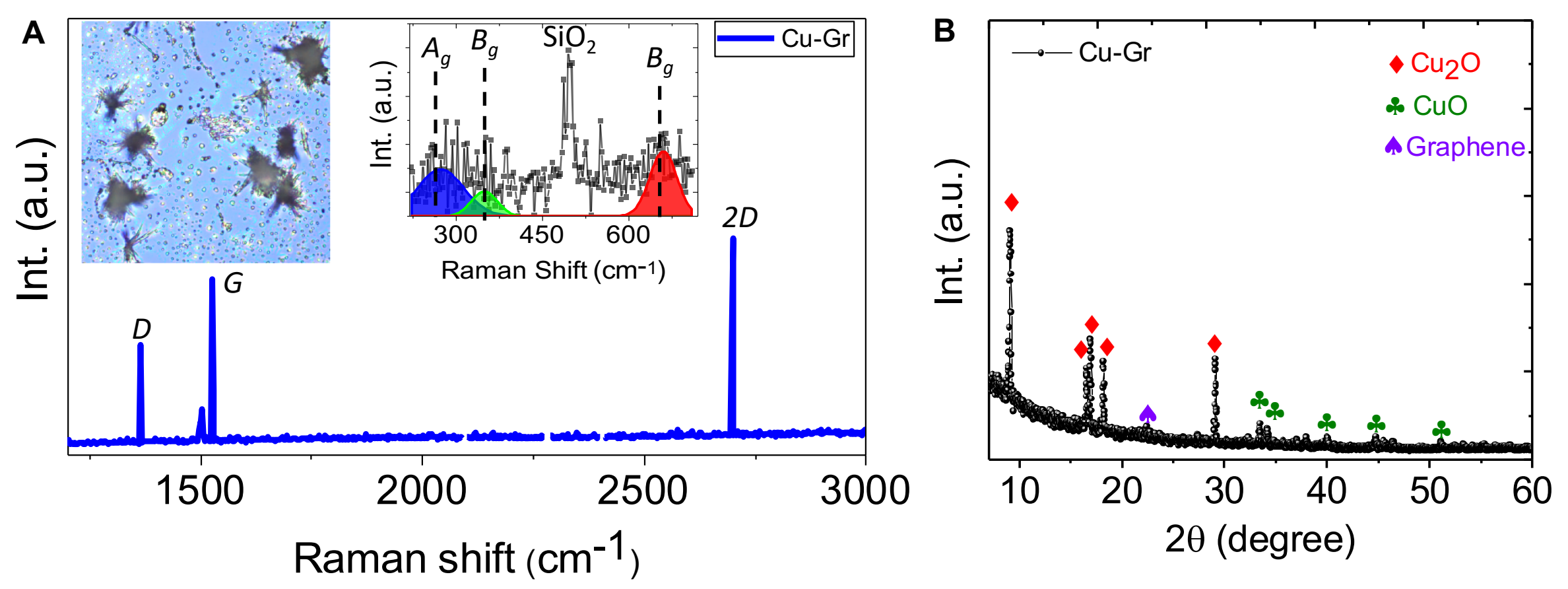
A

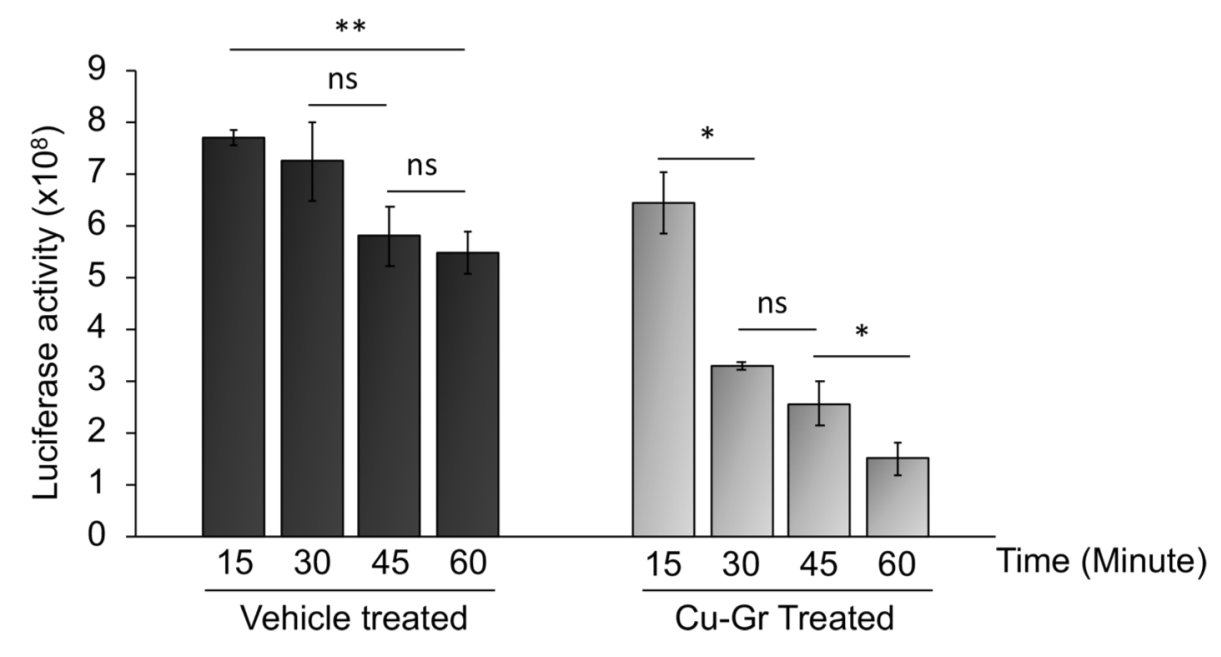

C

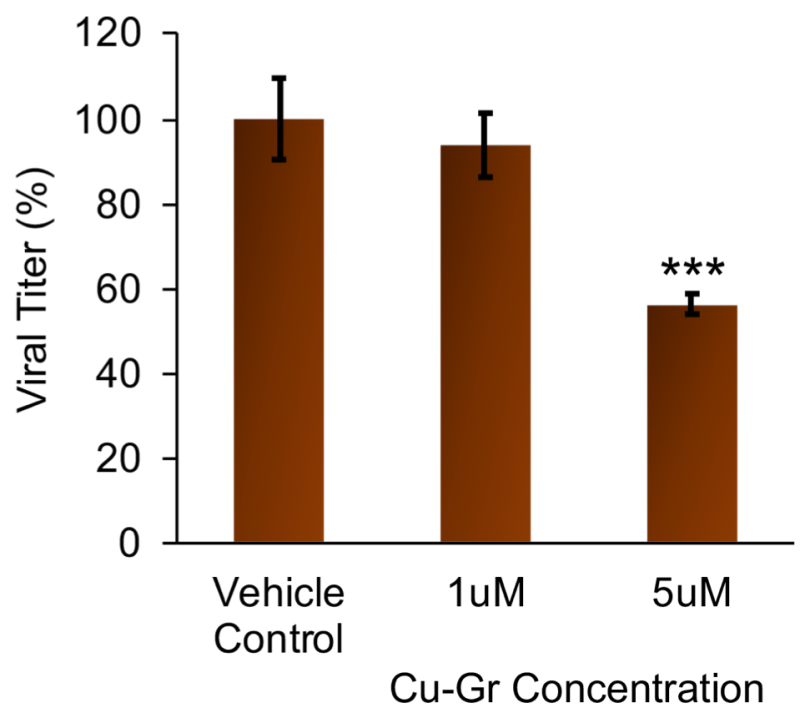

B

D

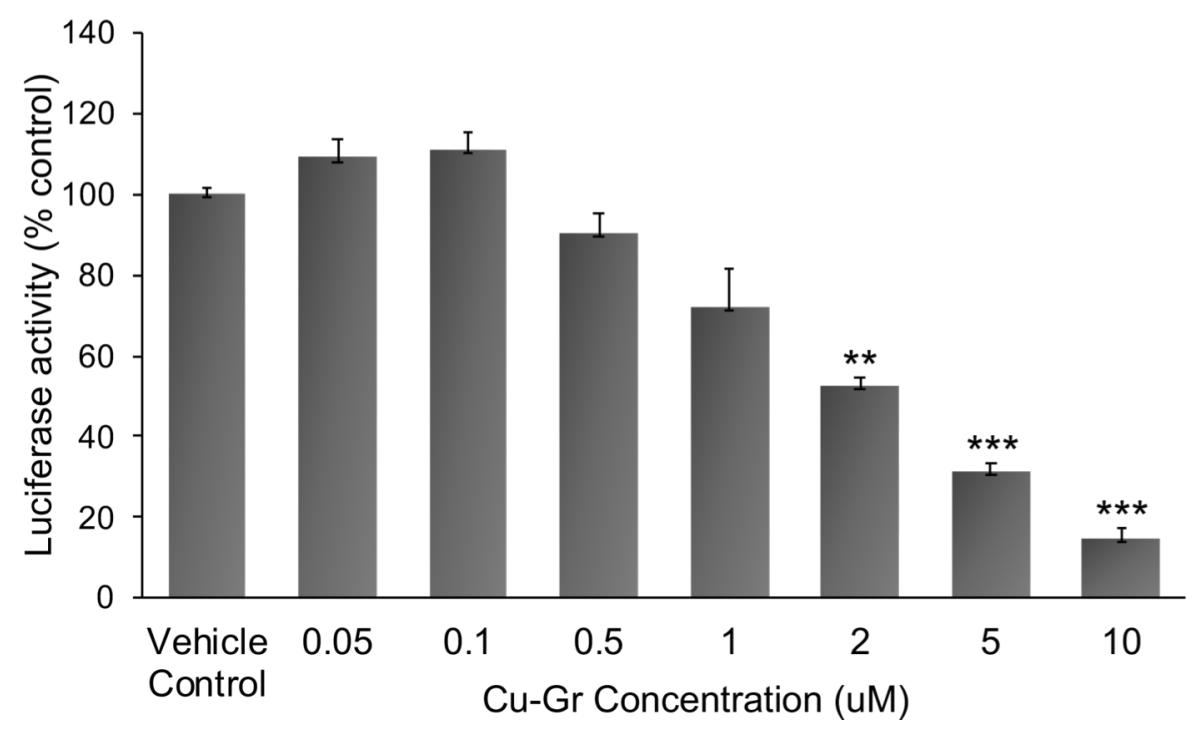

\begin{tabular}{|c|c|c|c|}
\hline \multirow{2}{*}{} & \multicolumn{3}{|c|}{ Viral titer (Pfu/ml) } \\
\cline { 2 - 4 } & Replicate-1 & Replicate-2 & Replicate-3 \\
\hline $\begin{array}{c}\text { Vehicle } \\
\text { Control }\end{array}$ & 57000 & 50000 & 55000 \\
\hline $\begin{array}{c}\text { Cu-Gr } \\
1 \mathrm{uM}\end{array}$ & 54000 & 48000 & 50000 \\
\hline $\begin{array}{c}\text { Cu-Gr } \\
5 \mathrm{uM}\end{array}$ & 29000 & 31000 & 31000 \\
\hline
\end{tabular}


A

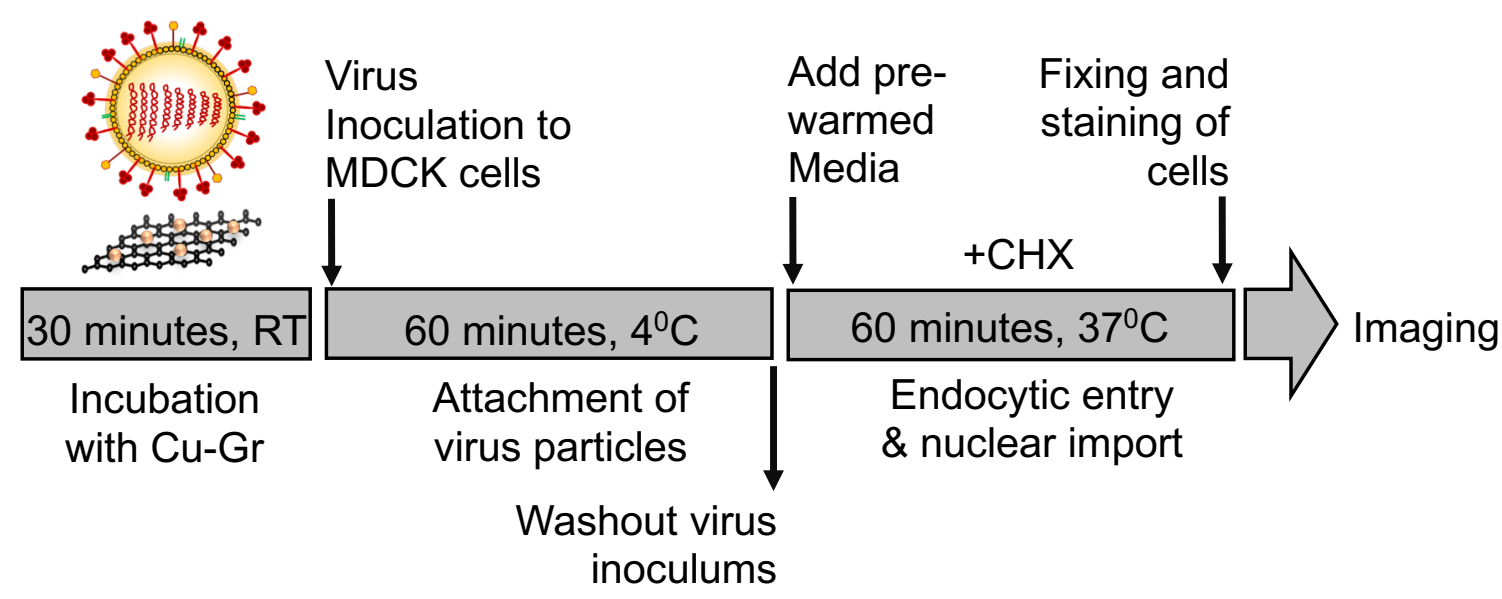

B

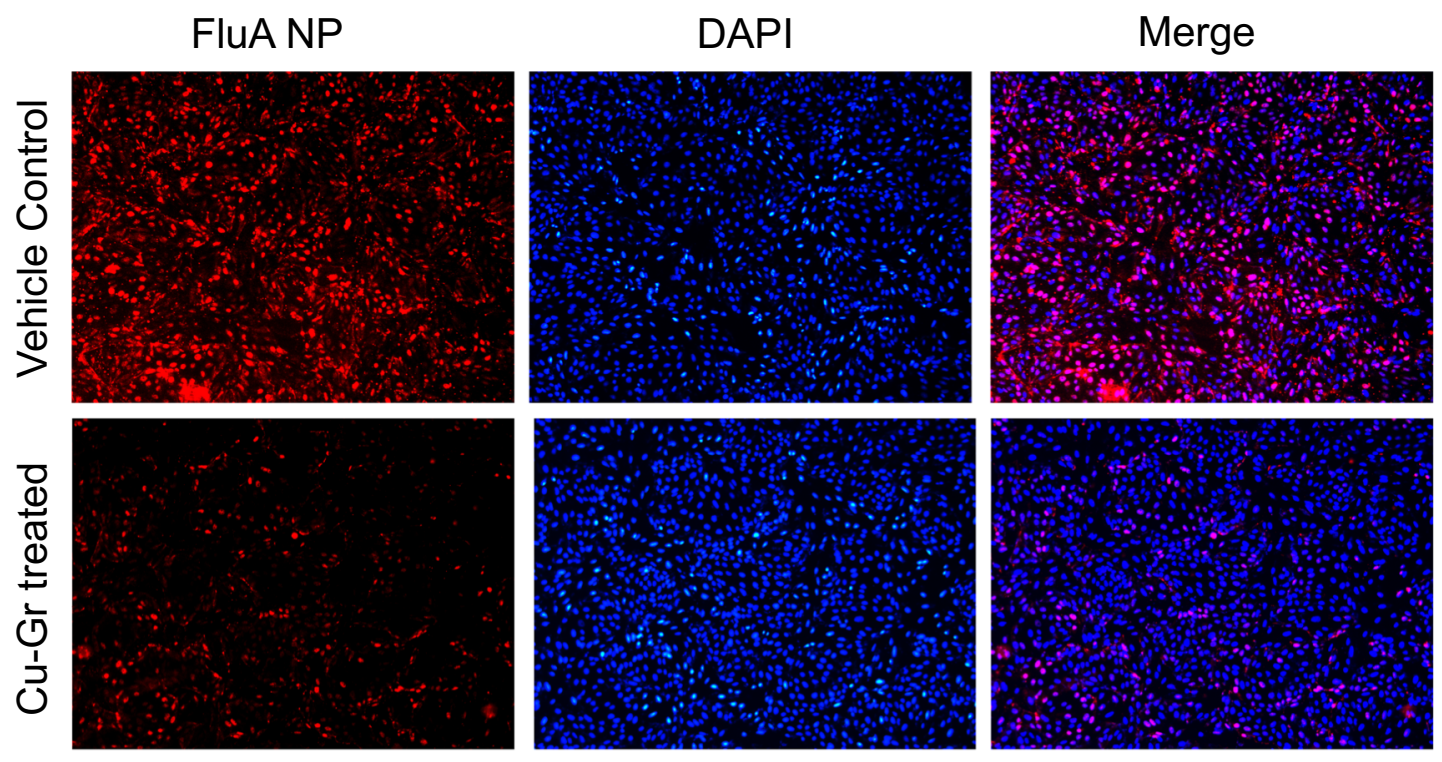

C

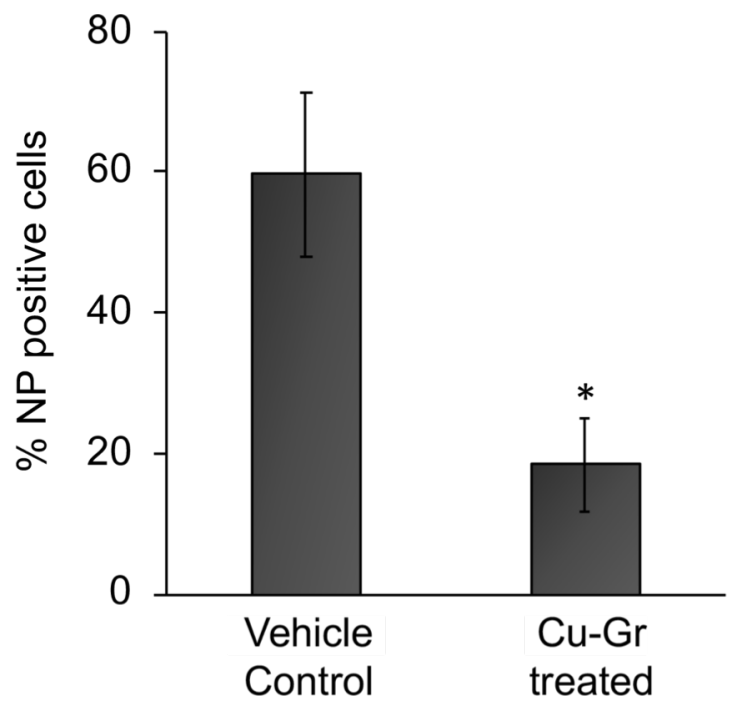


Figure 7

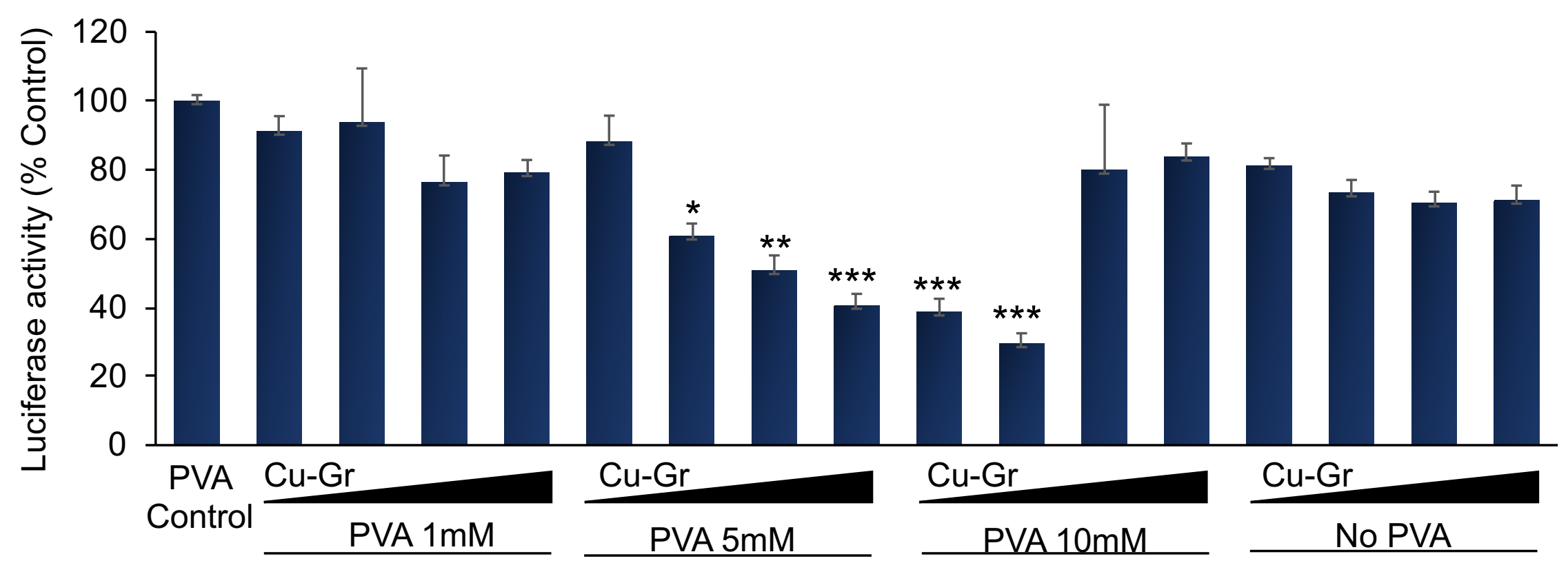




\section{Figure 8}

A

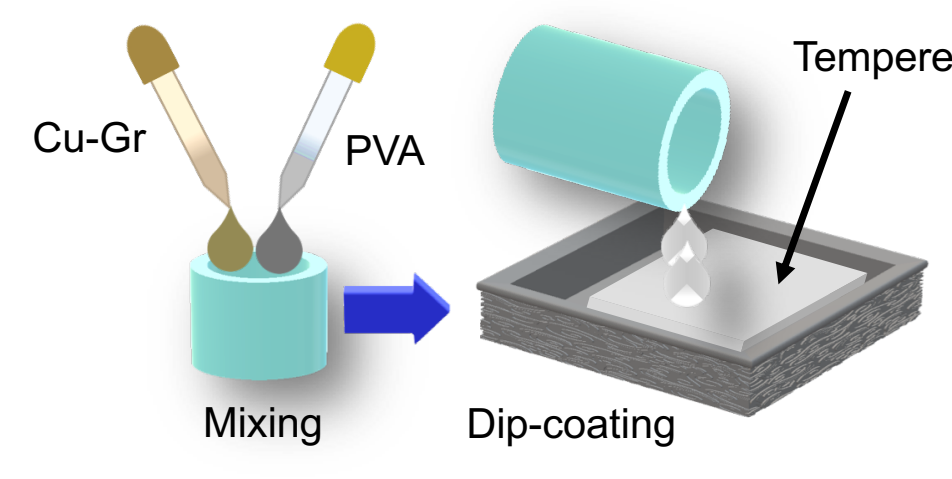

B

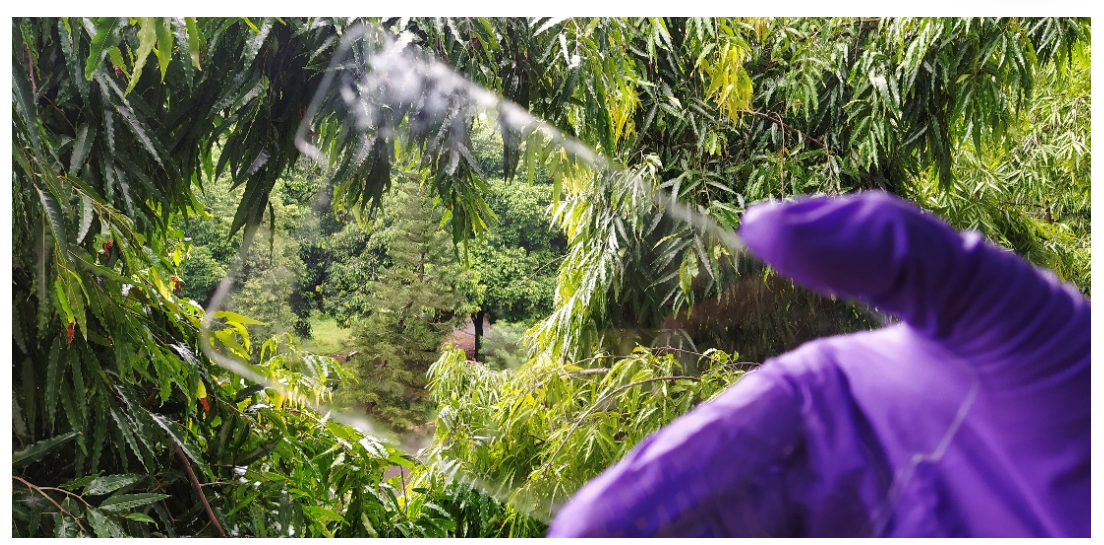

E
C

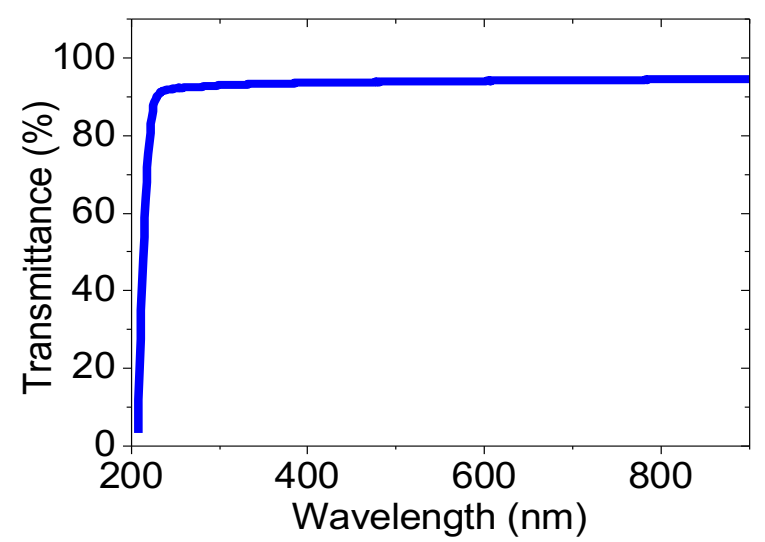

D
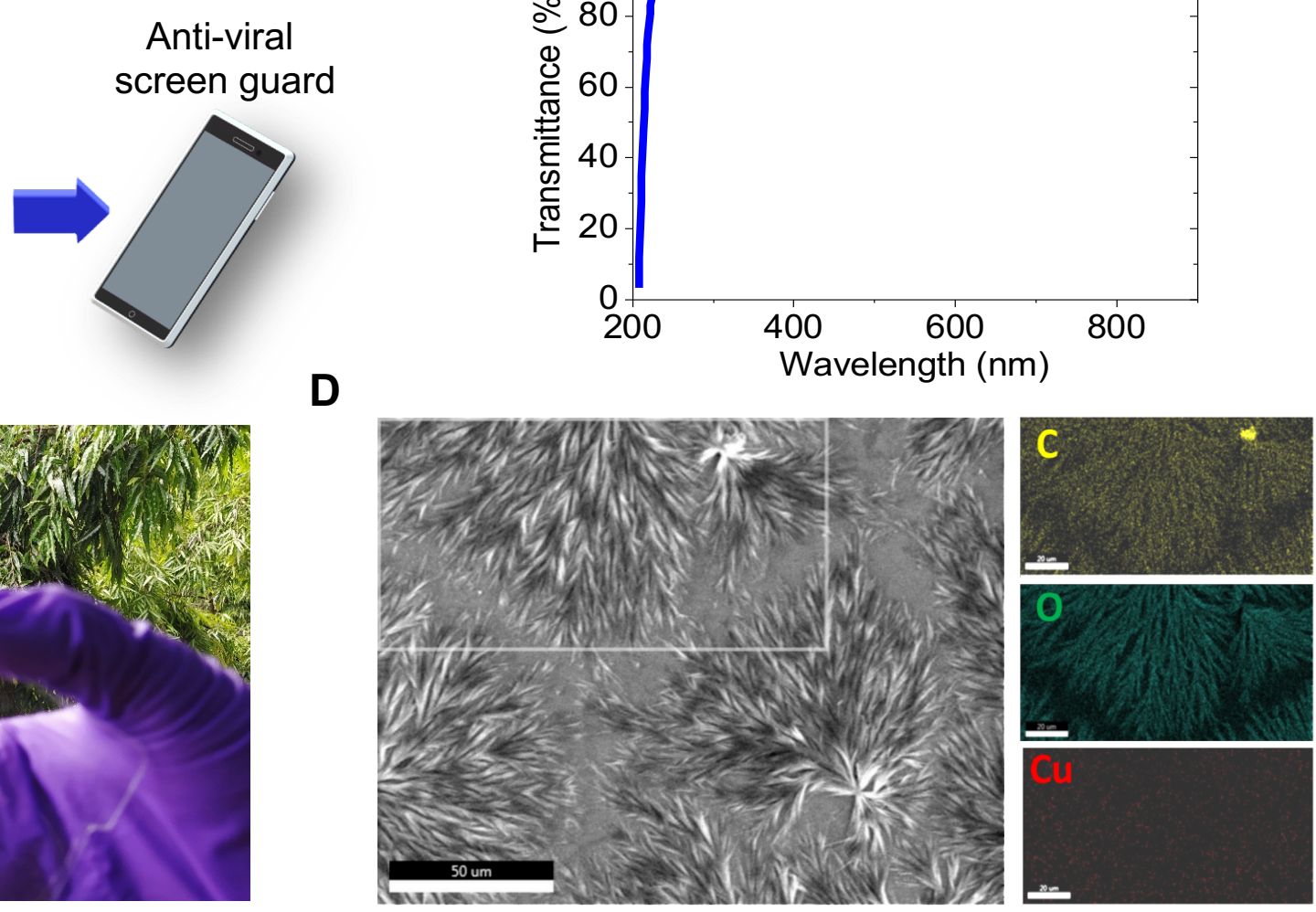

F

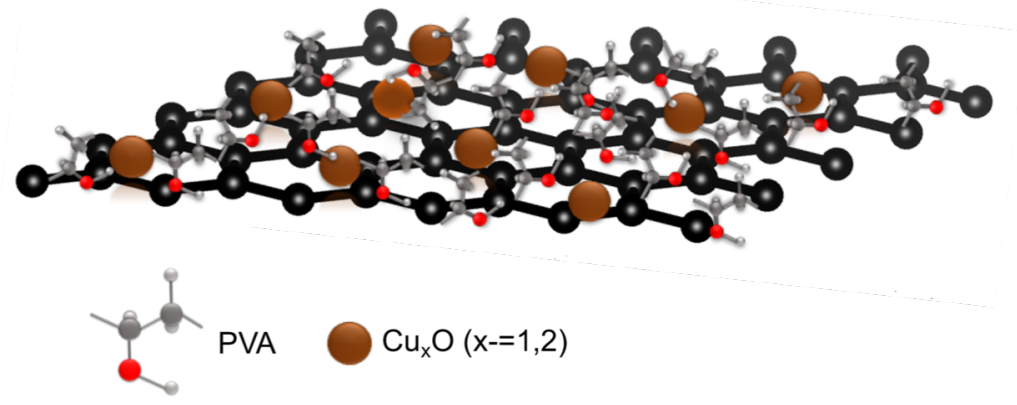

